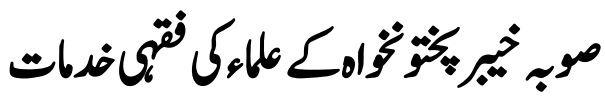

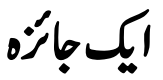

"Fiqhi" Contributions of the Ulama of Khyber Pakhtunkhwa Ananalytical Study

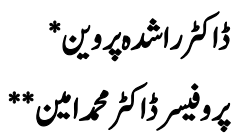

\begin{abstract}
"Fiqh" or "Al-Fiqh" is one of the most important fields of Islamic Religious Sciences. It deals with the nature and rulings of the practices usually observed by the Muslims in their daily lives regarding being lawful or otherwise. In this field, the contributions of the religious scholars of the province of Khyberpakhtunkhwa are highly admirable. Being a gate-way for the Sub-Continent including China, the scholastic pursuits progressing in Syria, Iraq and subsequently in Asia Minor, particularly impressed/influenced the Fiqhi developments of this region (Khyberpakhtunkhwa). The reason for the said influence on this specific area (region) has also been elaborated in this article. An massive creative work along with original research studies were carried out by the inhabitant scholars of the Sub-Continent in general and that of the Khyberpakhtunkhwa Province, in particular since long duly producing remarkable books in this field. There is another specific characteristic of the people of this region: that the majority of them are the followers of "Fiqh-e-Hanfi"
\end{abstract}

In this article, only as a sample, an analytical review of the books of "Ulema" hailing from this region (like Syed Amin -al-Haque", Maulana Shaista Gul", "Maulana Hamd-Allah-Jan" and "Sheikh-AlQuran, Maulana Muhammad Tahir") has been presented to prove the above-cited hypothesis.In addition to that all of the above details and some more have been elaborated along with special focus on the creative works of the Religious Scholars of this region. Most of the research works- (other than those mentioned in this article) are published in the forms of presentable books. This will prove helpful for the young researchers in future.

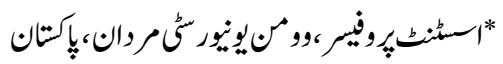

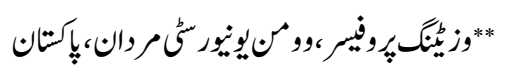


Key Words: Fiqh Hanfi, Islamic Religious Sciences, Khyber Pakhtunkhwa, Scholastic pursuits

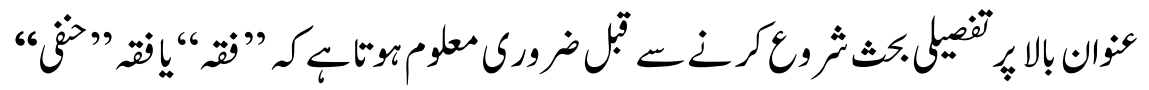

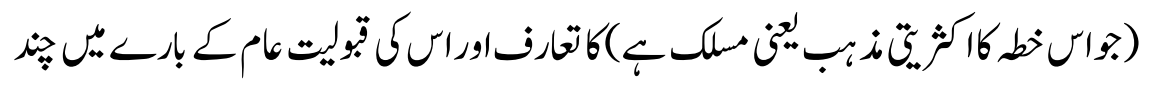

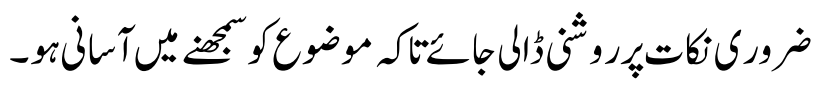

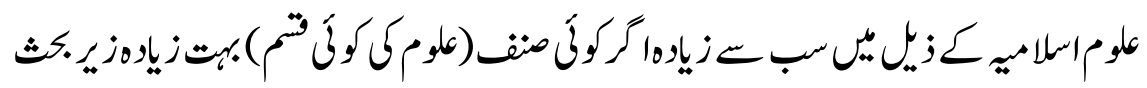

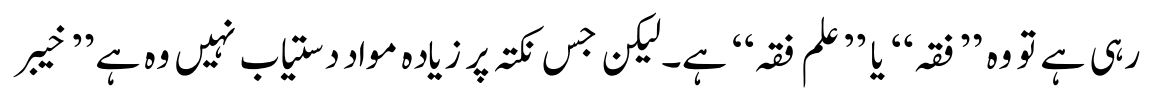

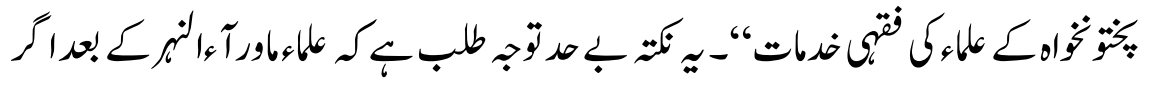

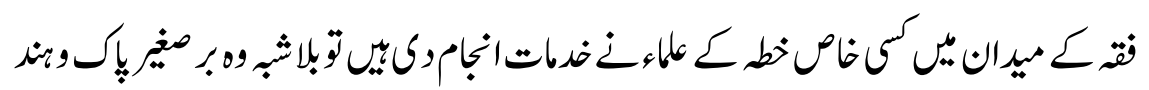

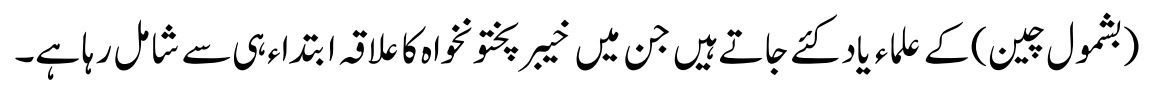

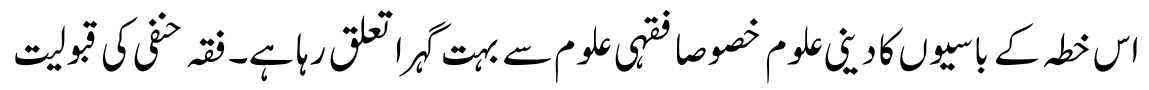

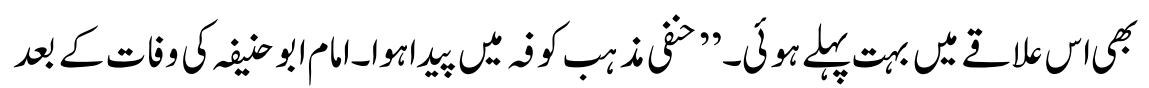

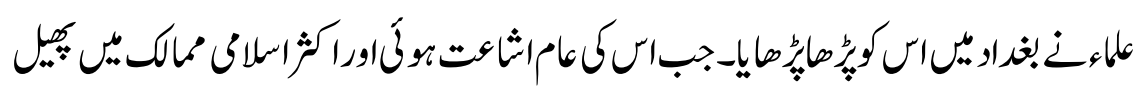

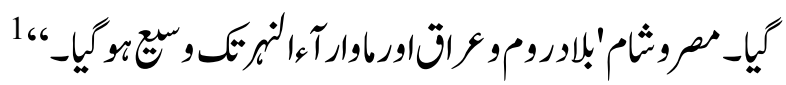

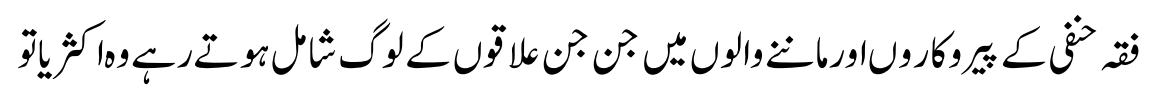

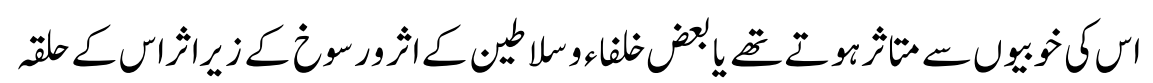

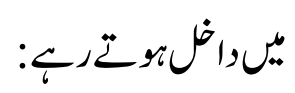

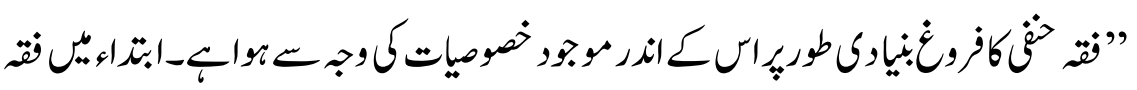

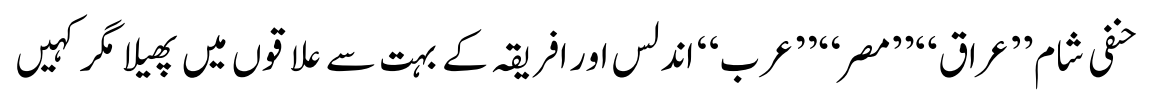

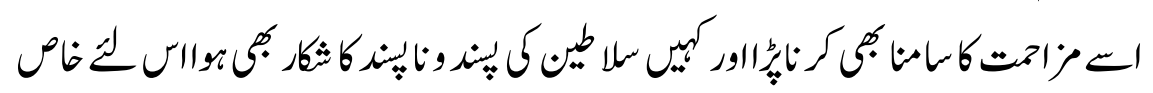

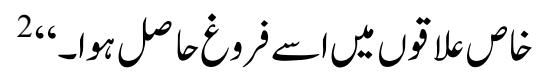

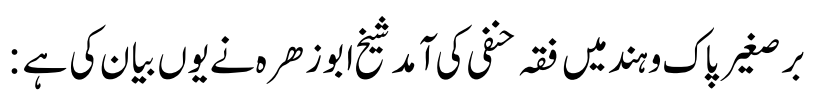




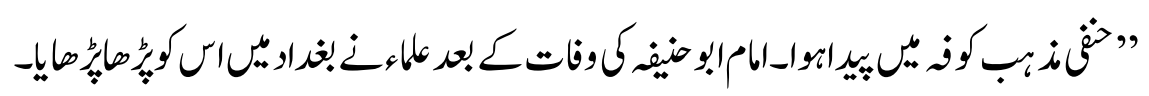

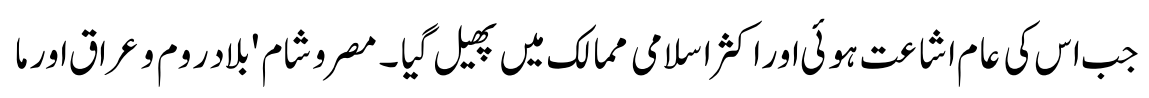

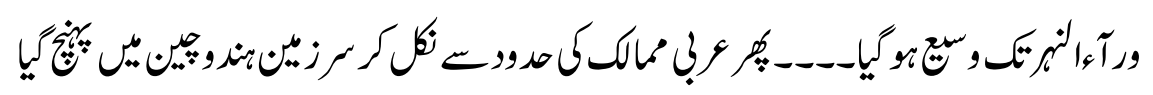

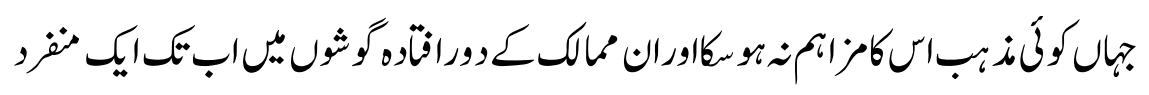

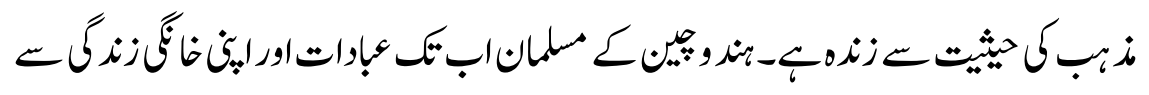

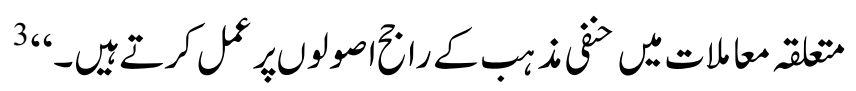

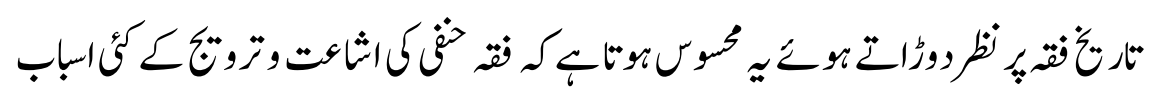

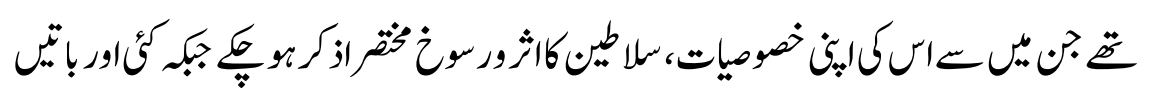

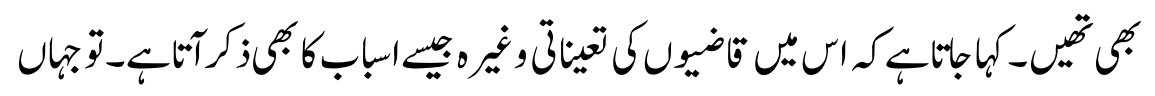

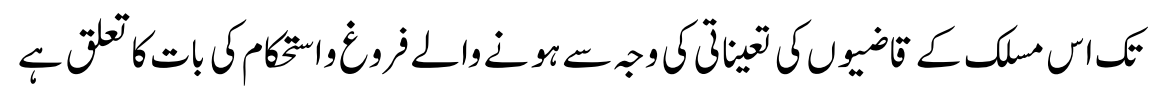

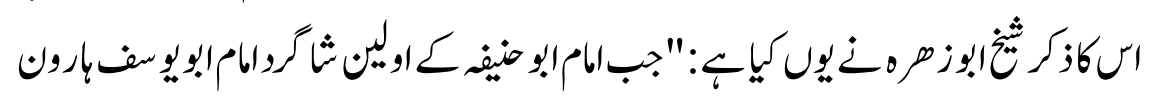

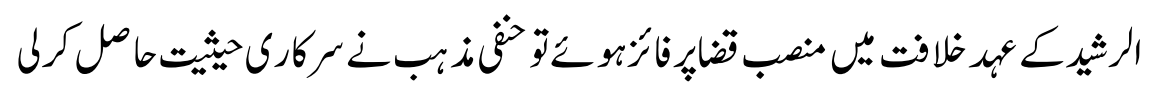

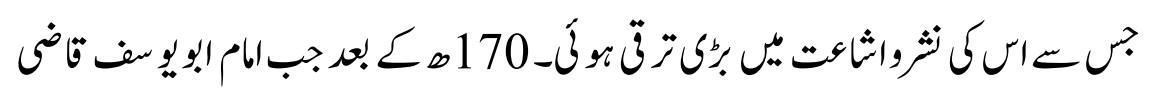

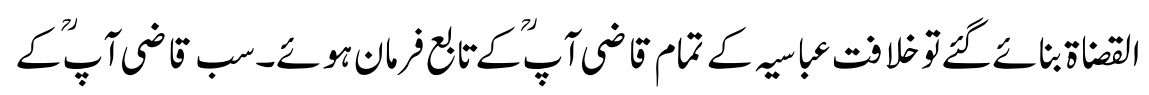

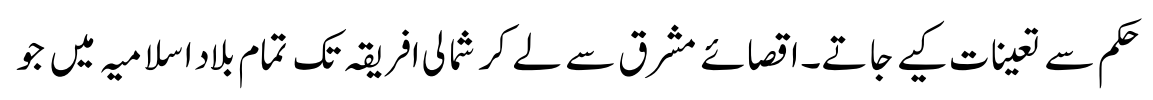

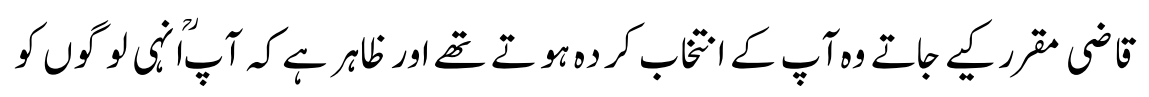

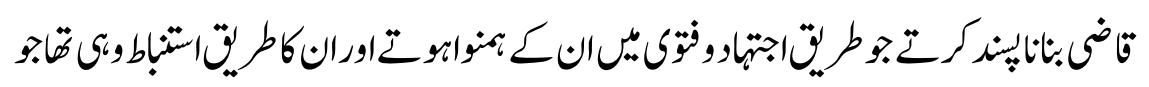

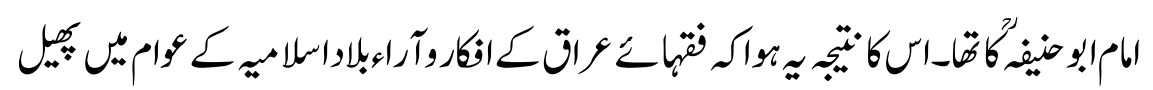

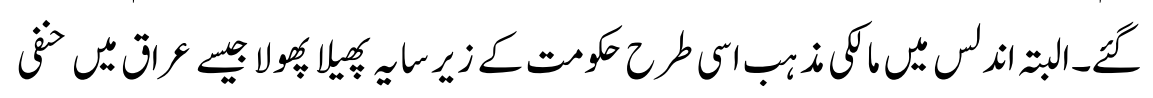

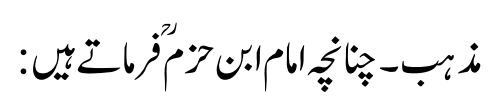

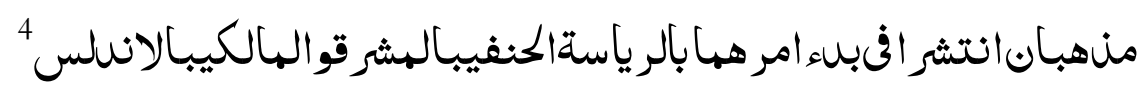




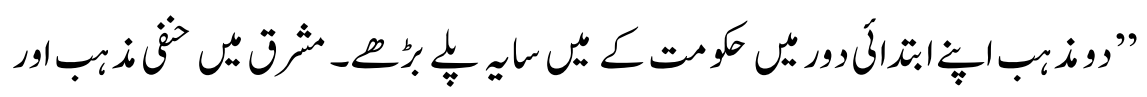

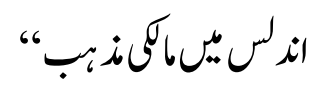

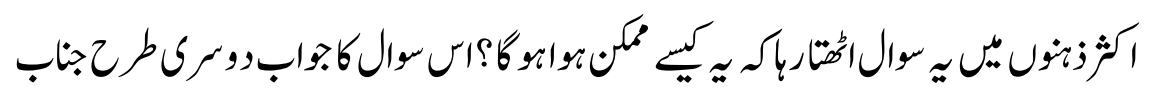

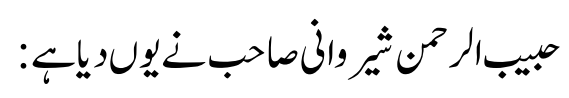

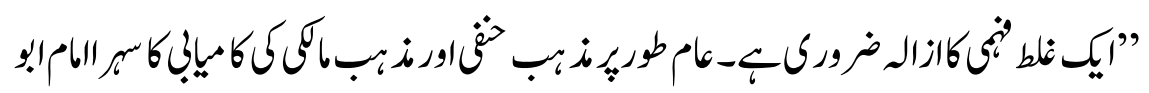

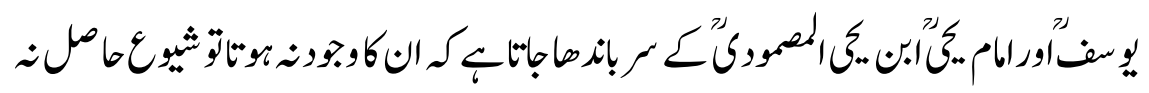

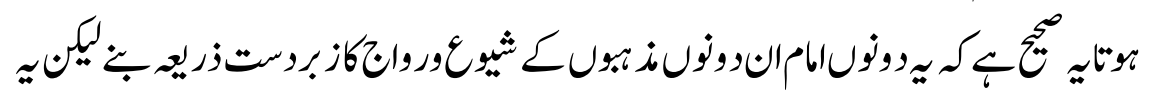

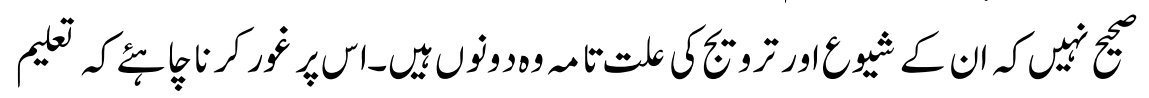

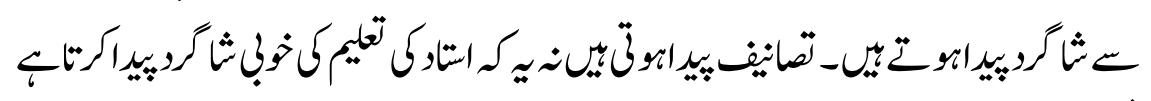

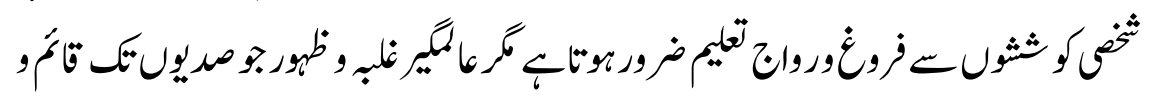

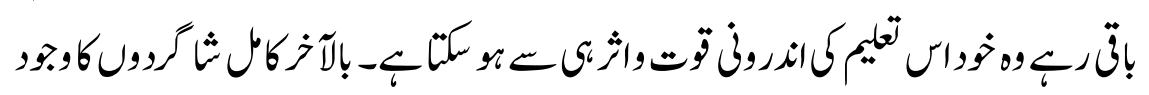

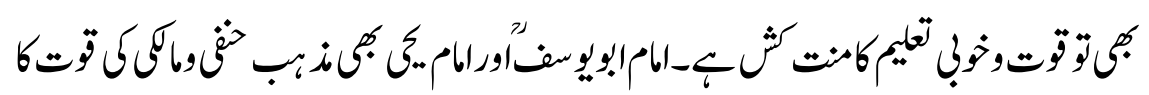

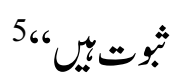

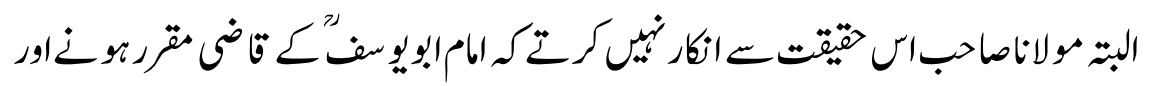

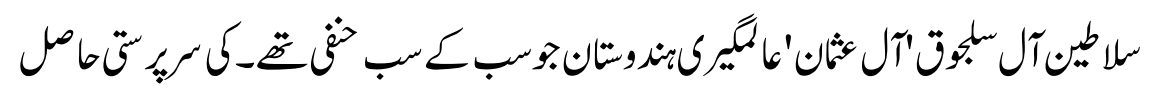

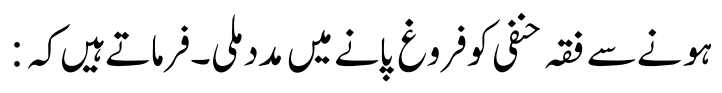

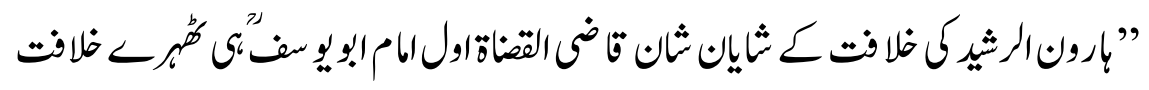

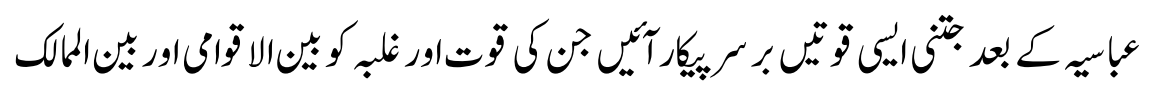

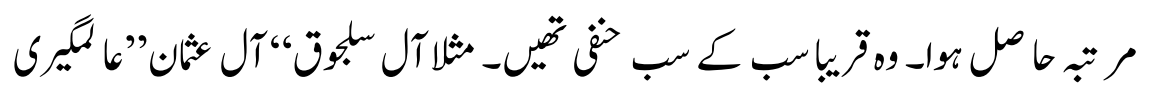

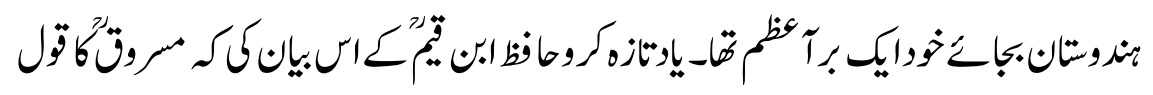

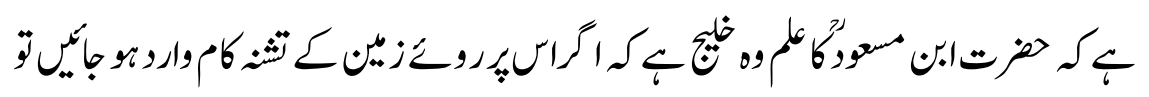




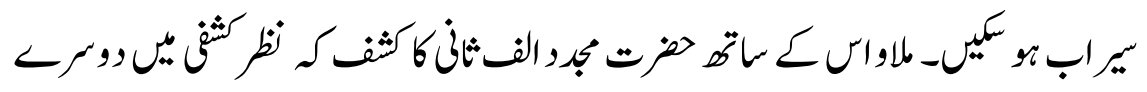

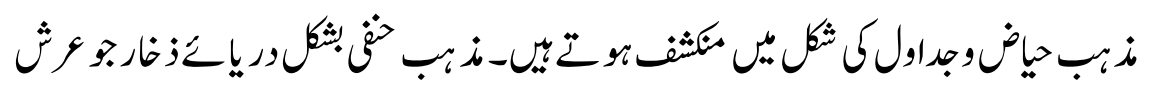

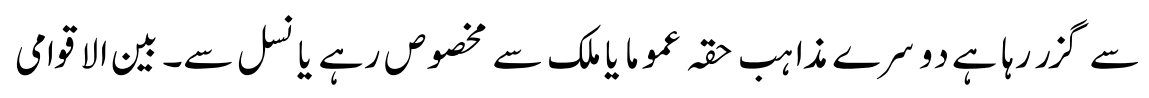

$$
\text { مرتبكتربإست_ }
$$

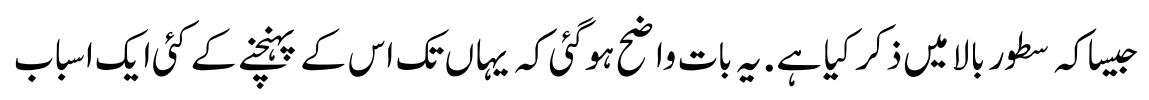

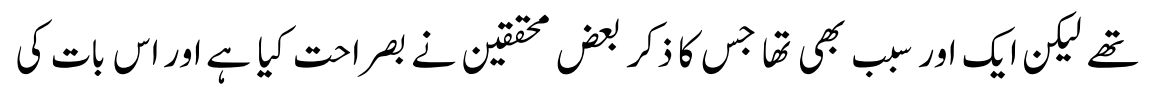

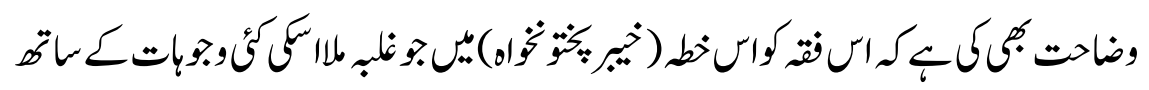

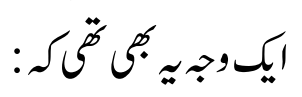

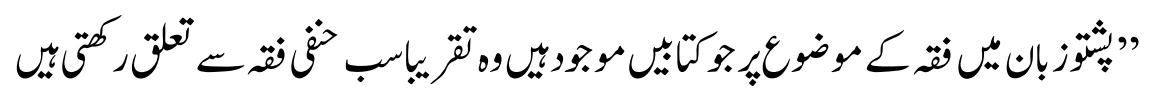

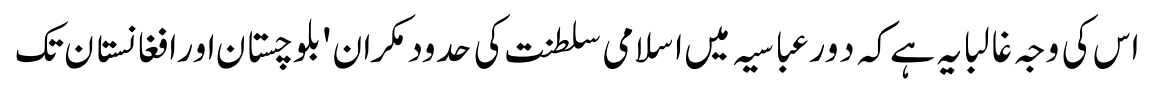

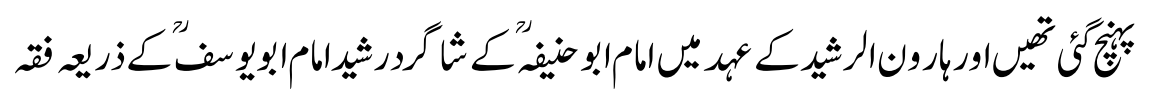

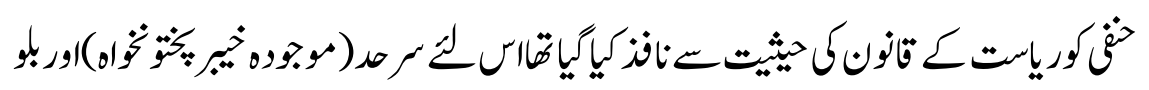

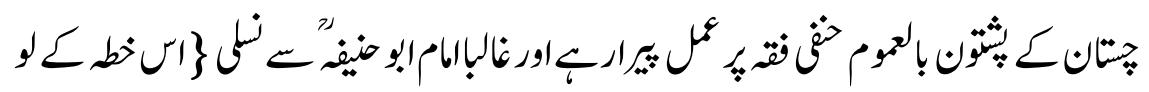

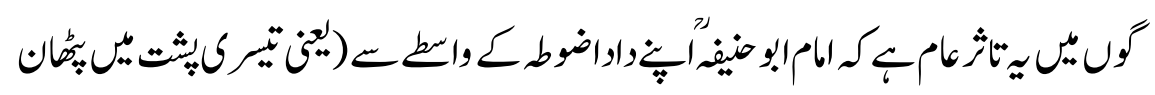

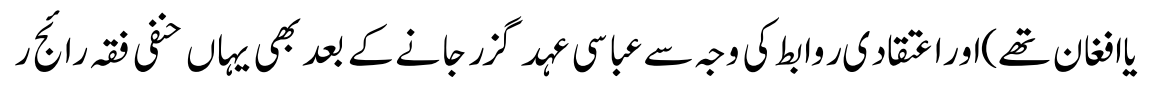
7 ' $\{-4$

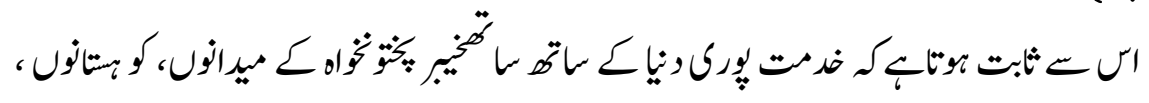

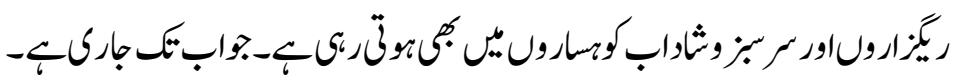

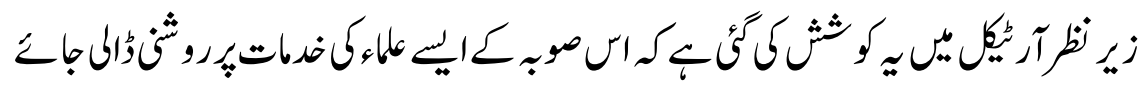

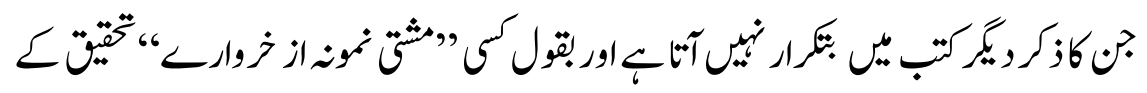

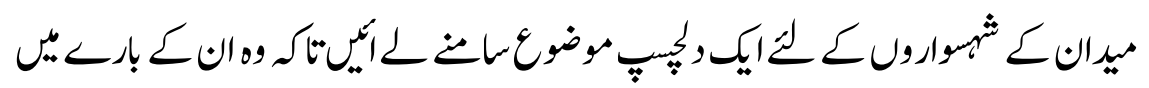

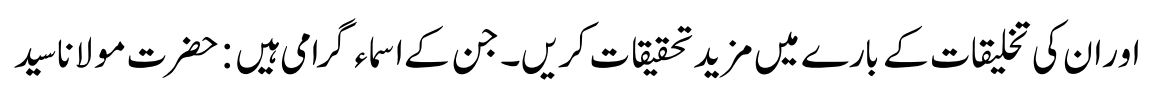




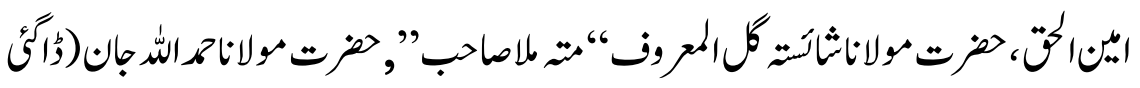

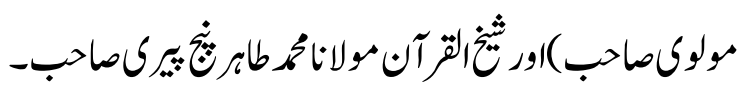

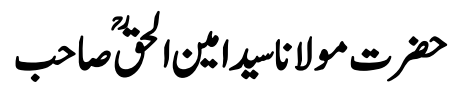

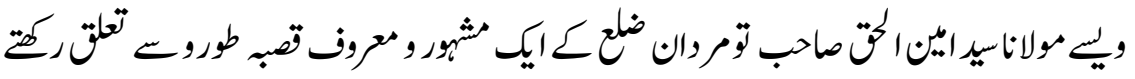

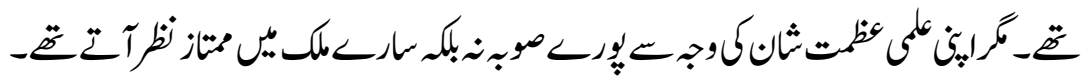

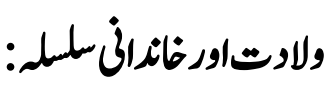

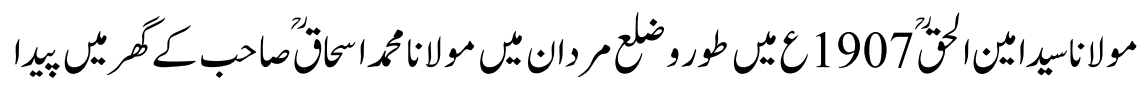

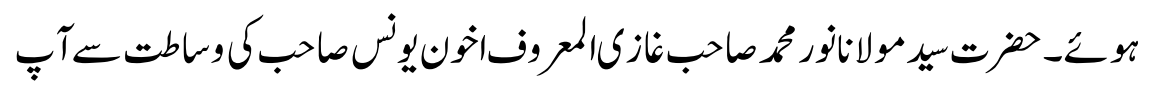

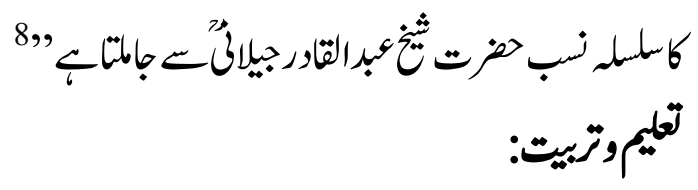

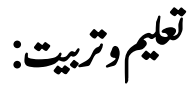

سياميرثاماحبك بيان كمطاتق:

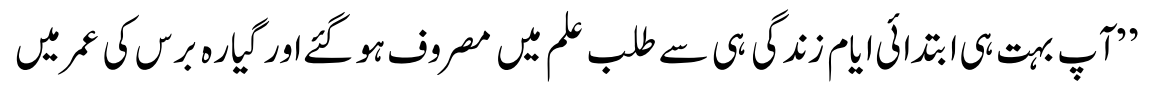

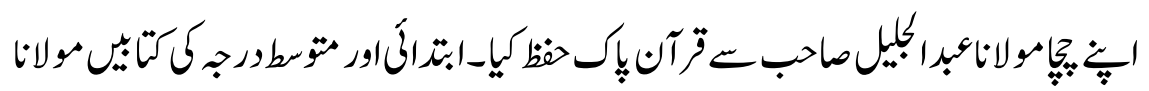

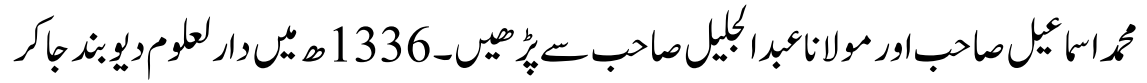

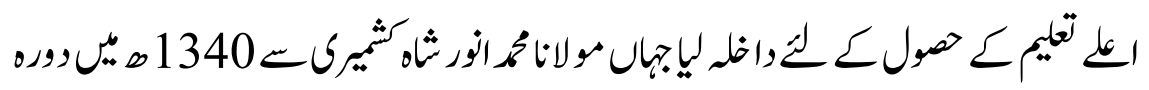

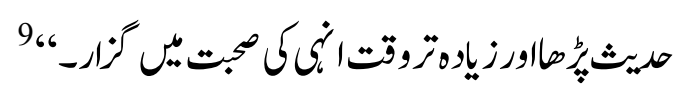

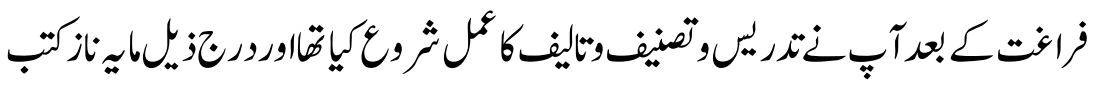
تصنيف كي:

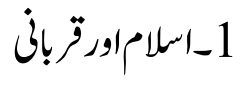

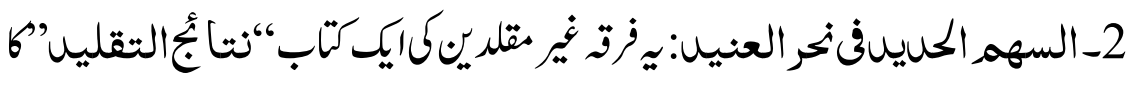

$$
\text { جوابك }
$$

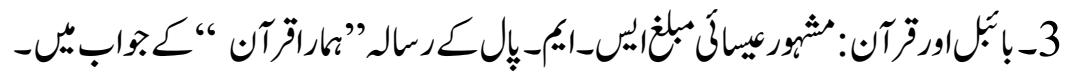




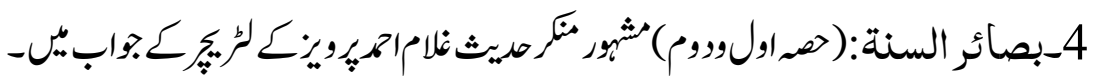

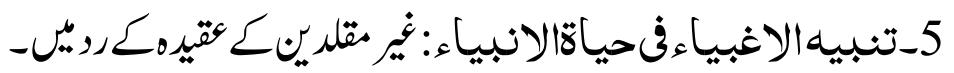

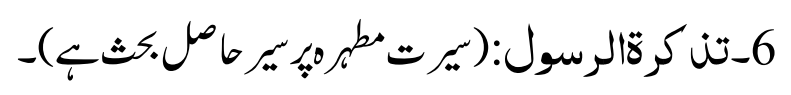

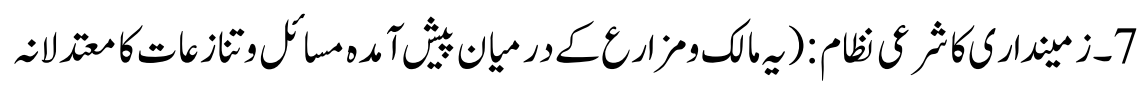

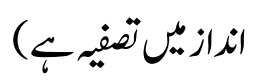

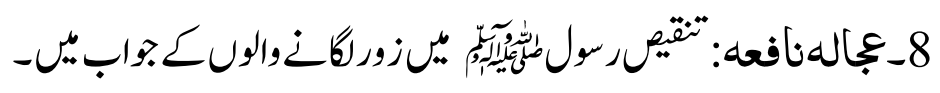

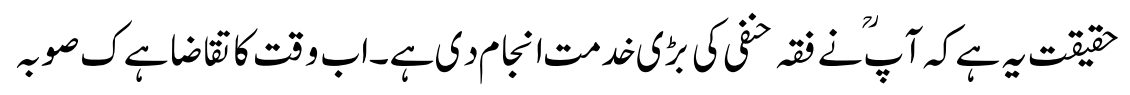

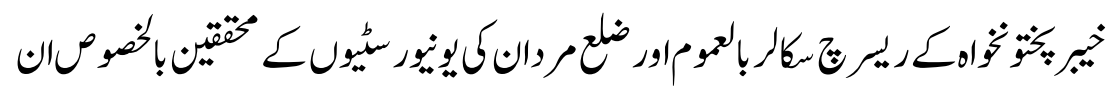

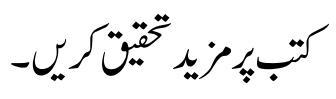

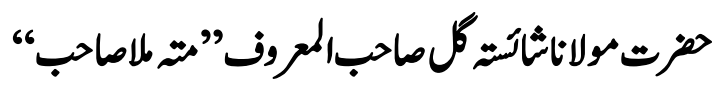

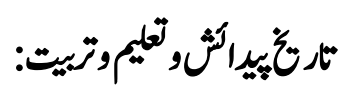

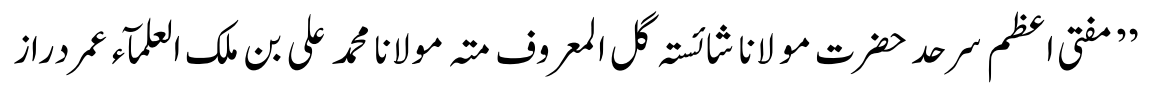

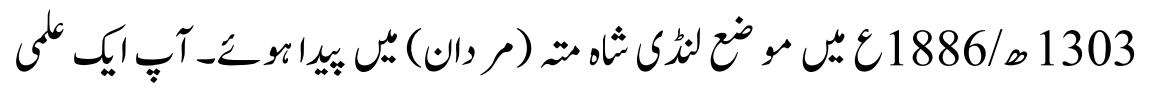

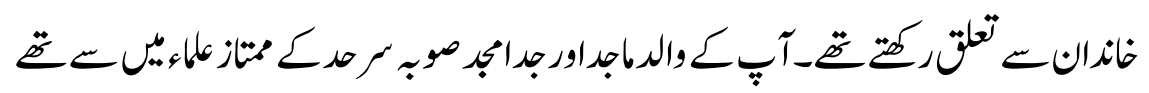

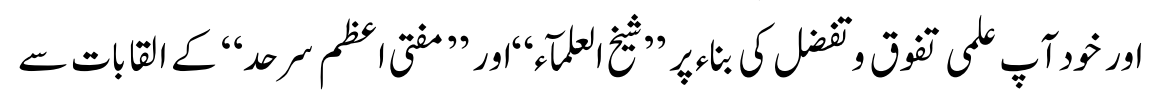

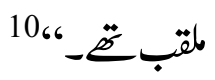

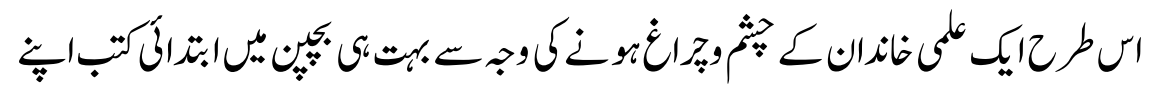

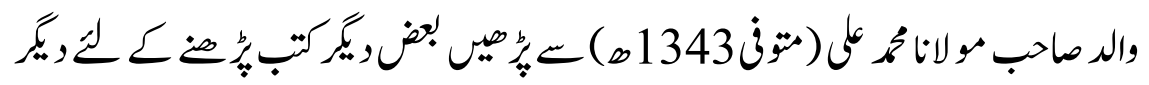

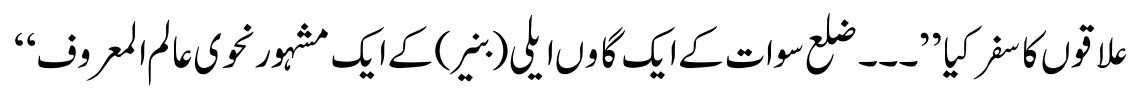

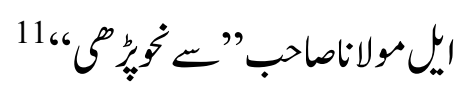

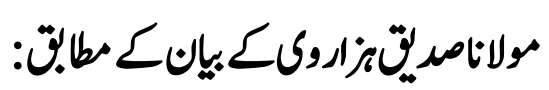




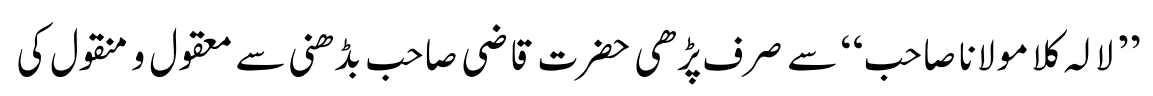

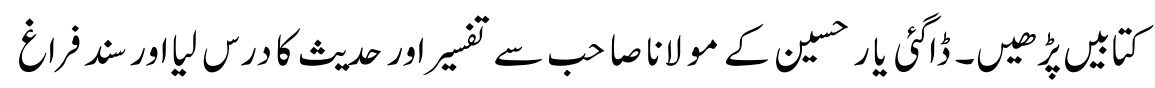

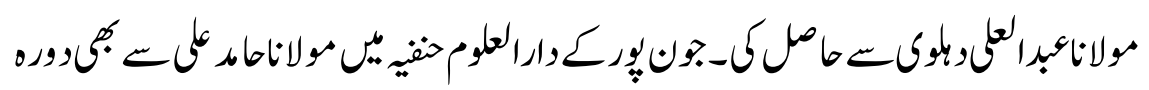

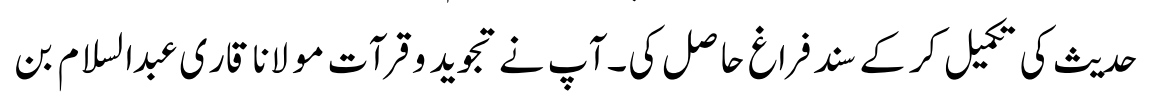

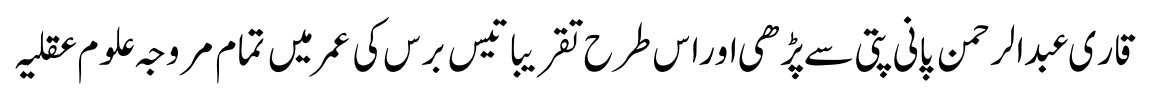

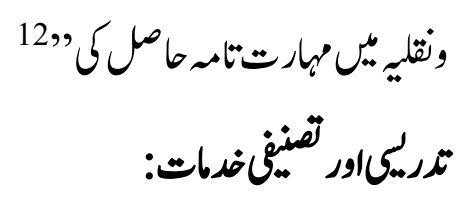

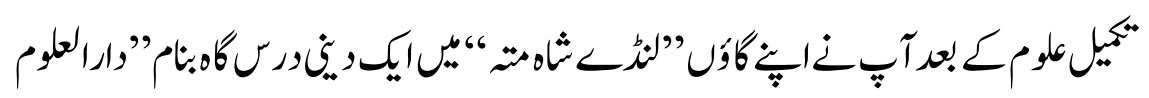

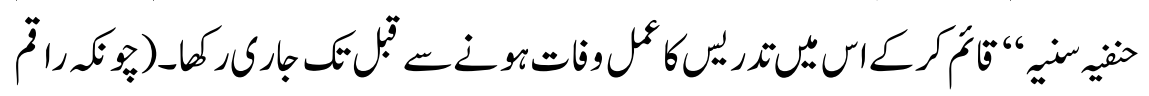

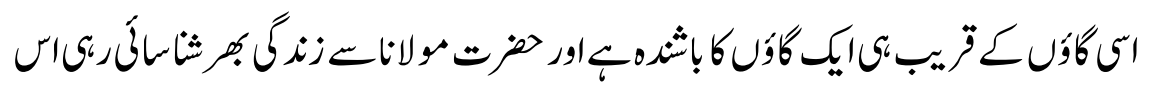

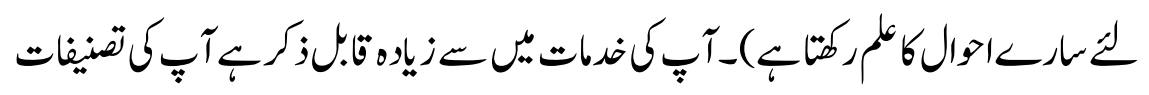

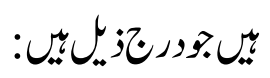

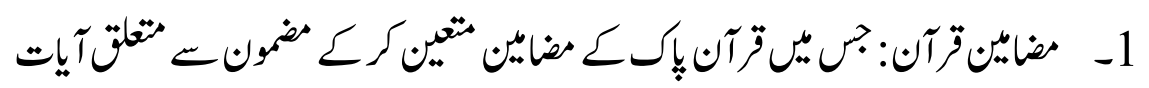
ترتيبرى تَئ-

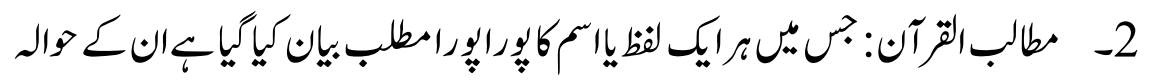

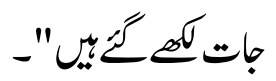

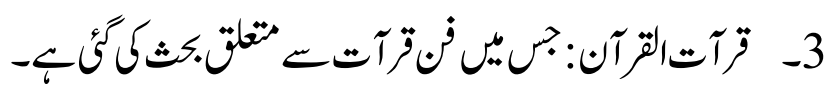

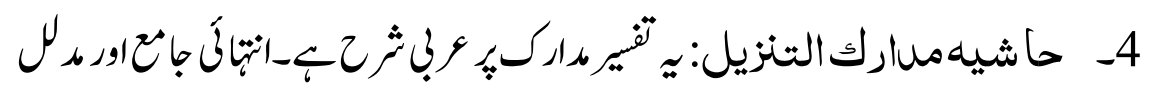

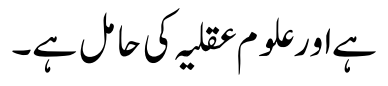

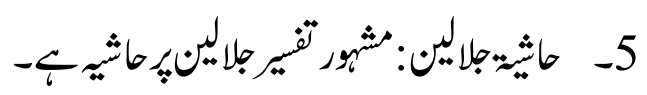

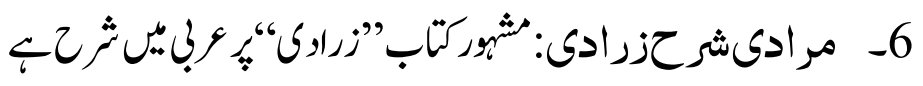




$$
\text { 7- }
$$

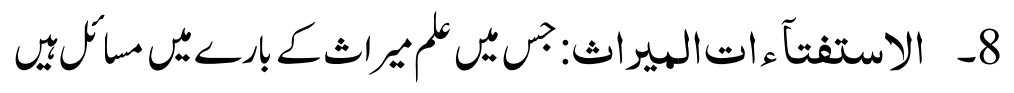

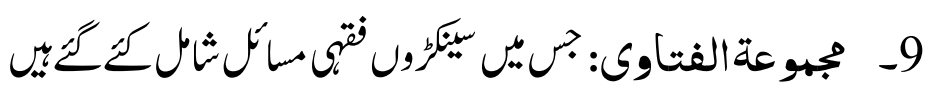

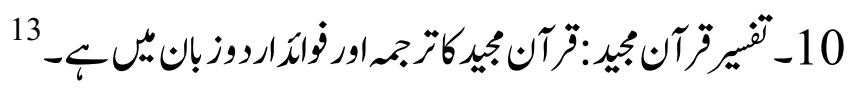

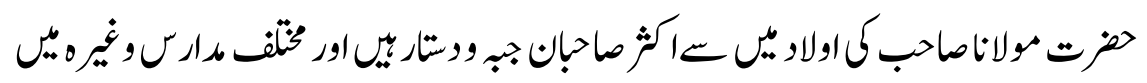

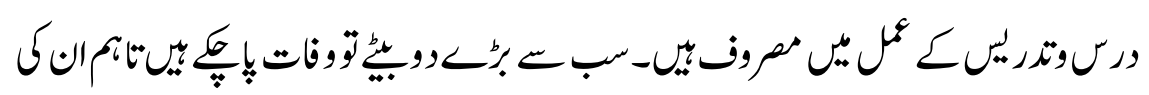

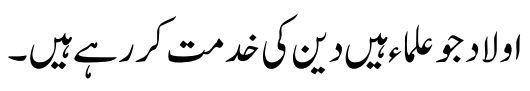

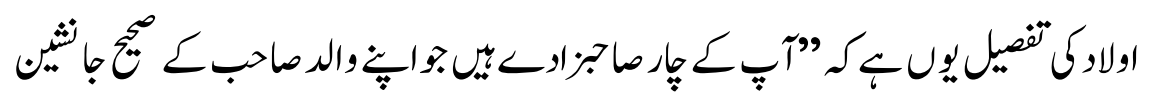

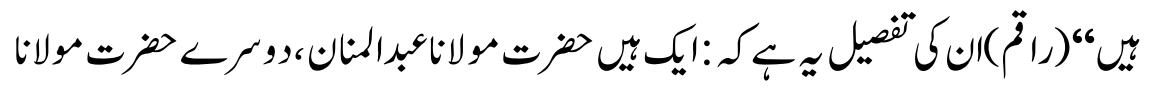

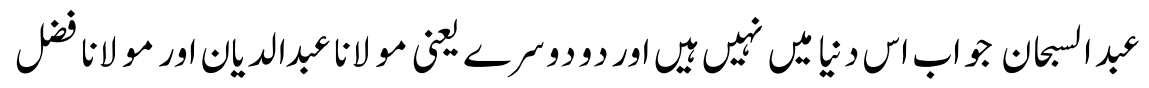

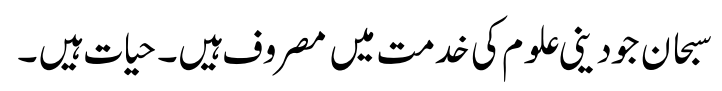

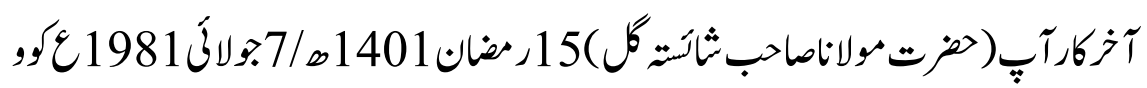

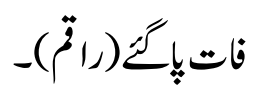

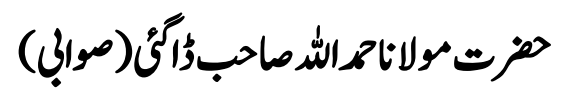
ولارت|ور تهيموتربيت:

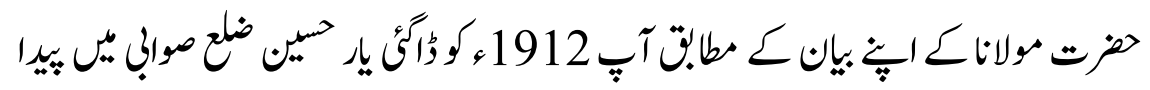

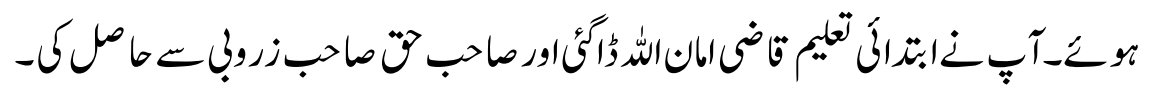

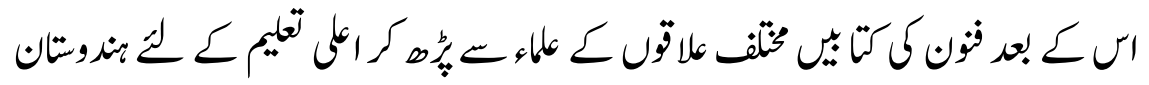

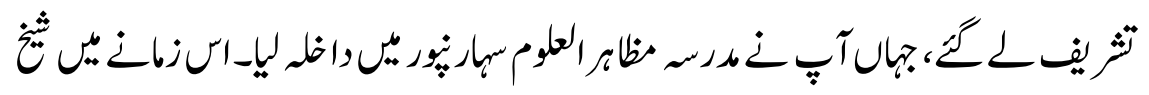

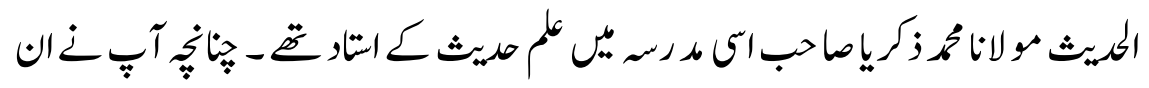




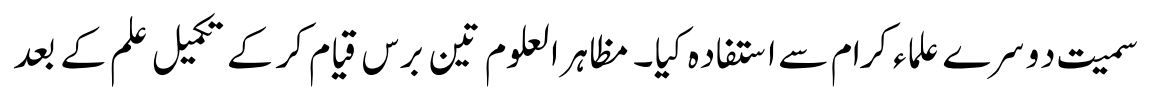

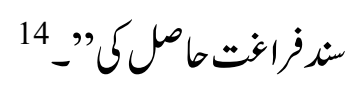

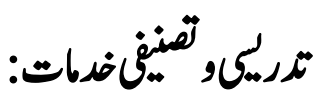

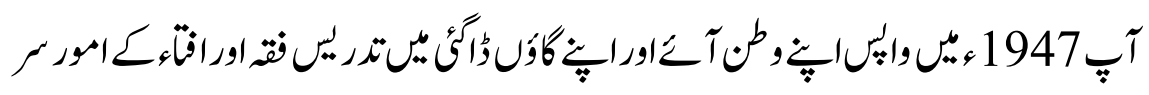

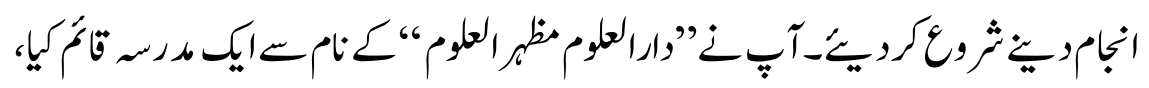

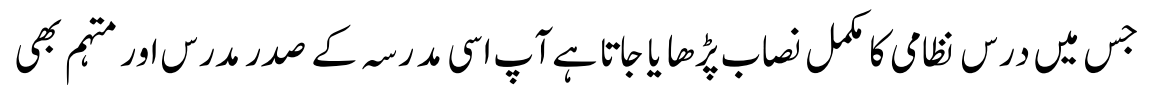

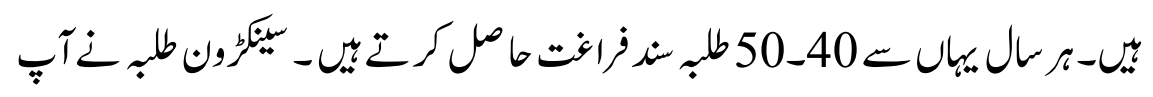

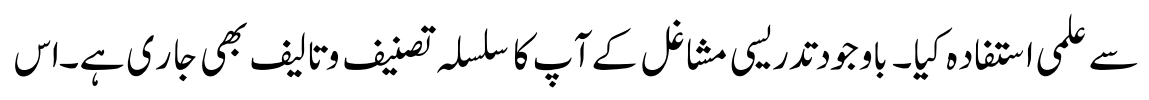

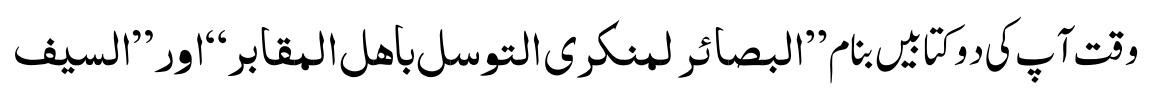

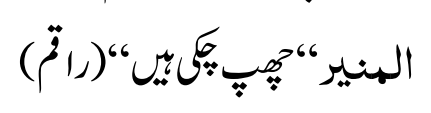

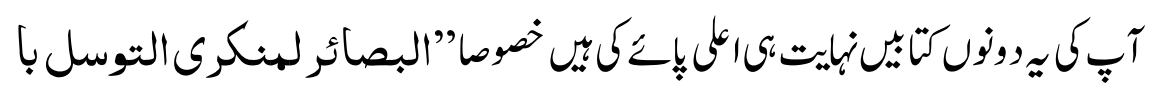

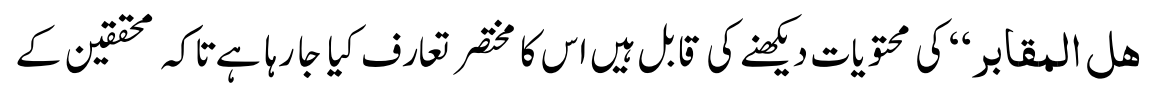

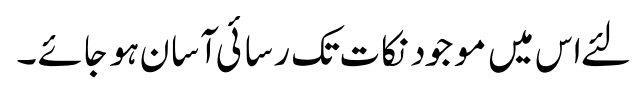

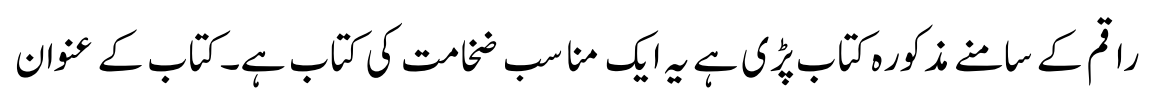

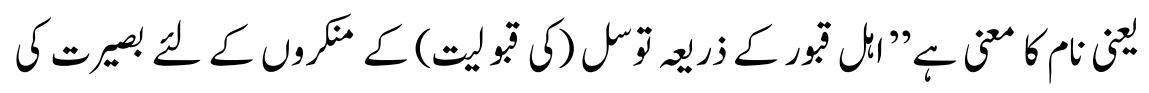

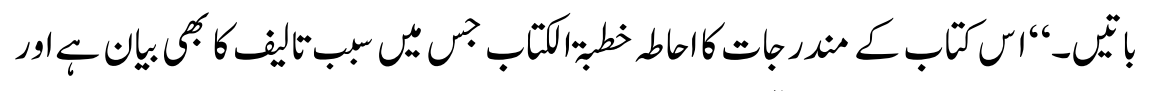

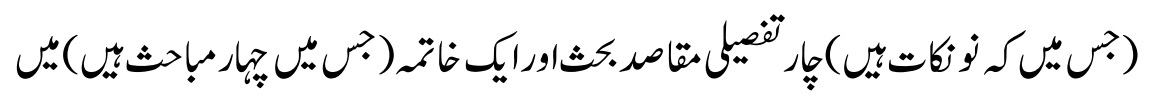

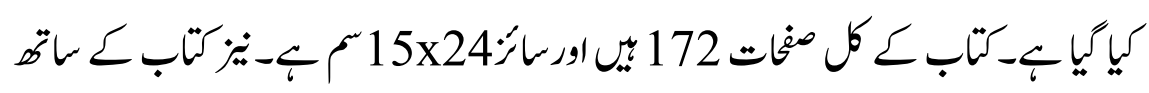

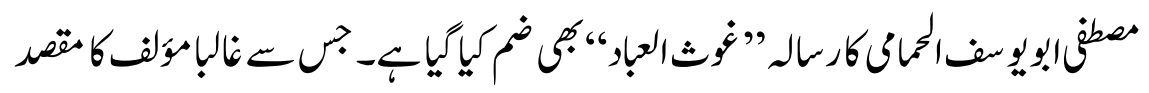

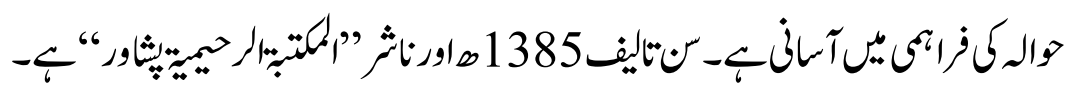

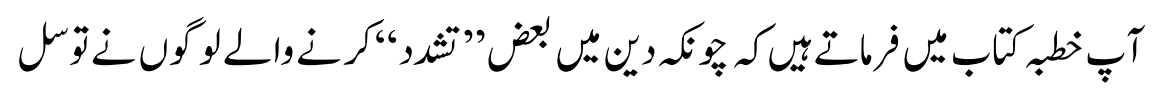

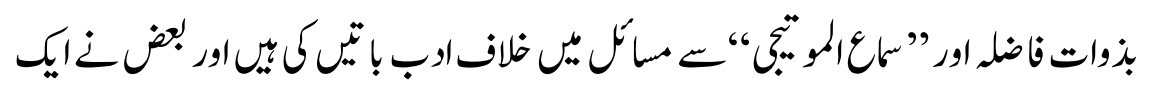




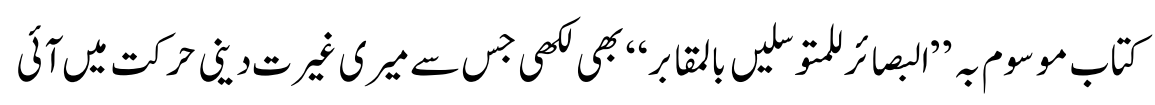

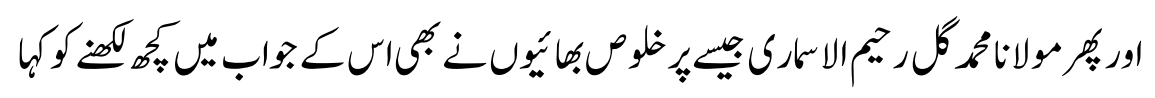

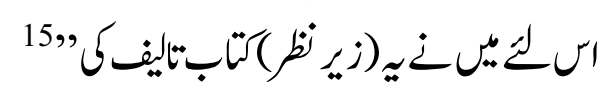

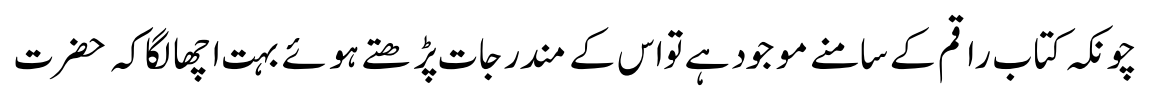

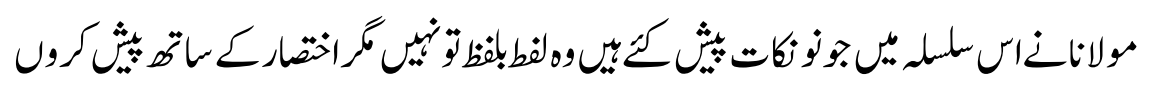

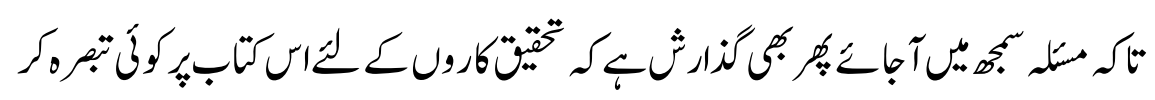

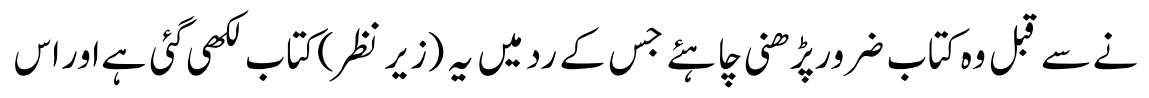

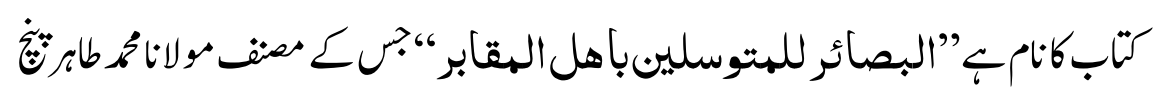

تيركيّ-

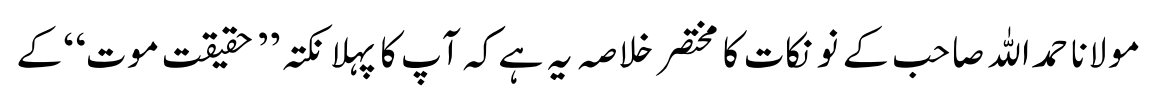

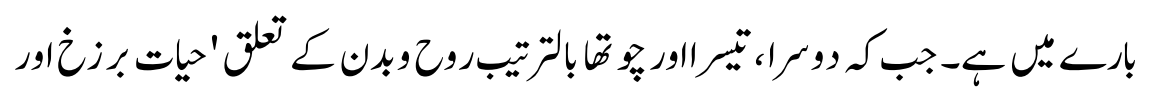

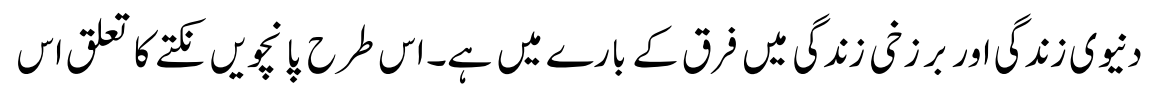

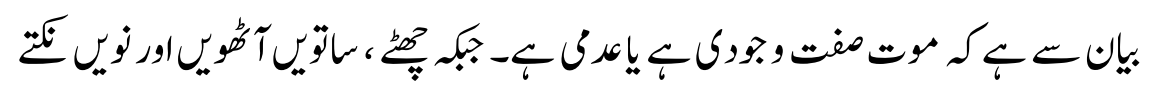

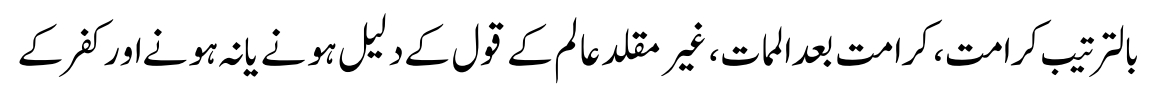

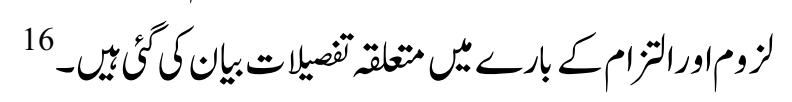

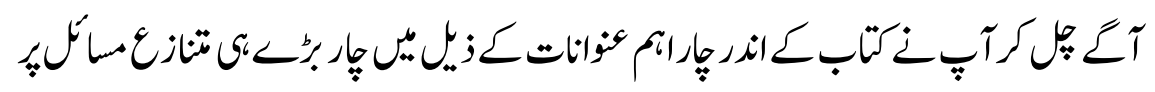

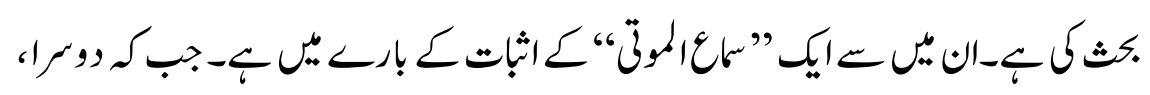

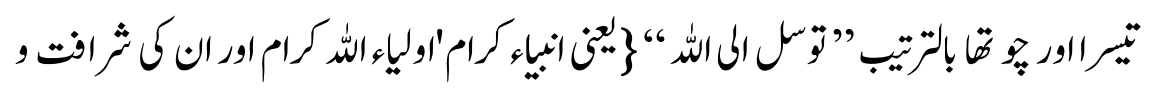

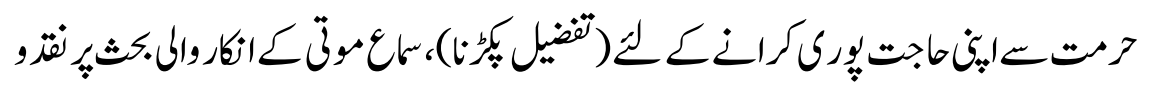

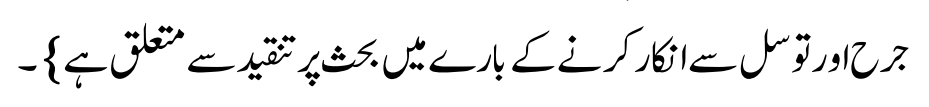




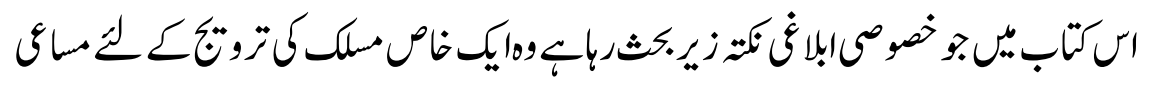

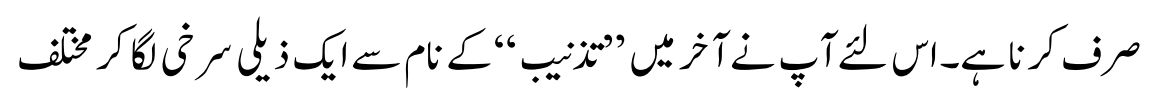

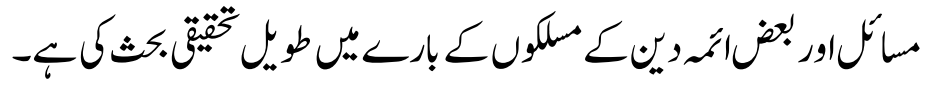

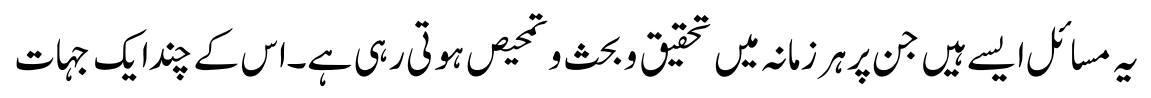

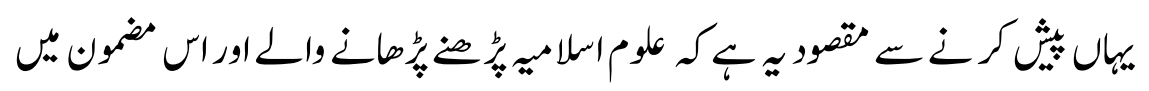

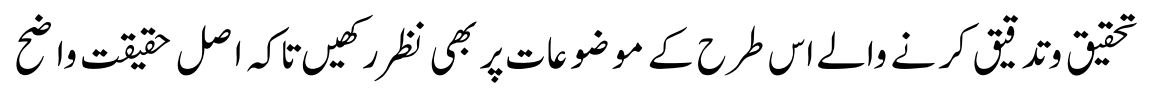

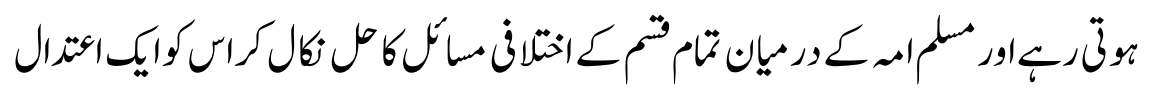

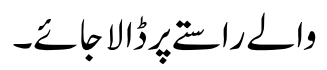

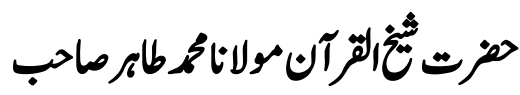

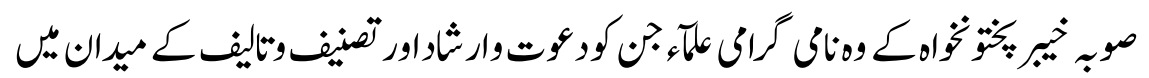

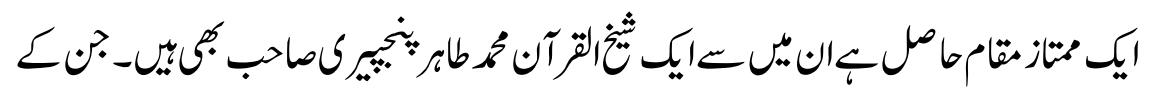

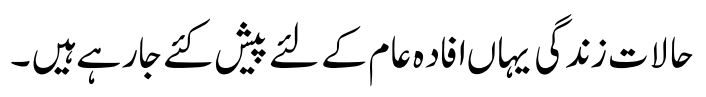

\section{بي الثَاور تحليموتربيت:}

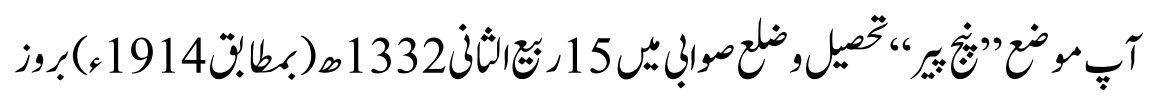

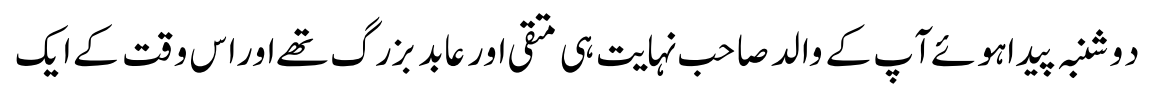

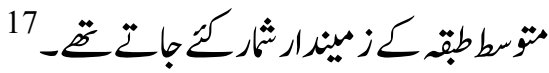

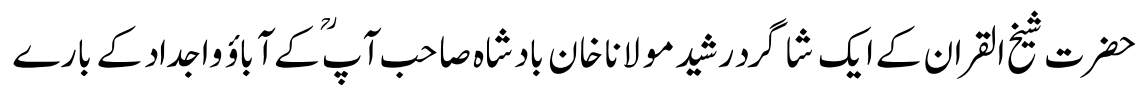

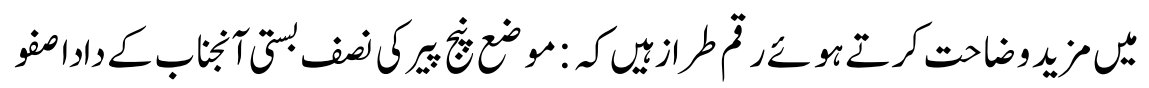

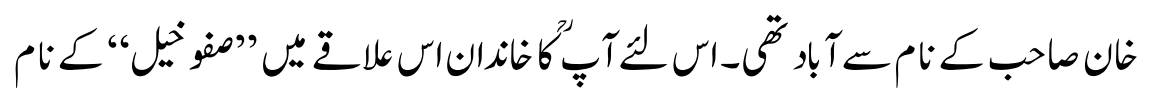




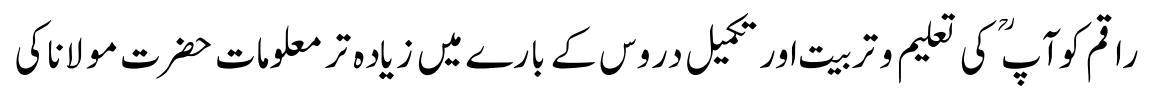

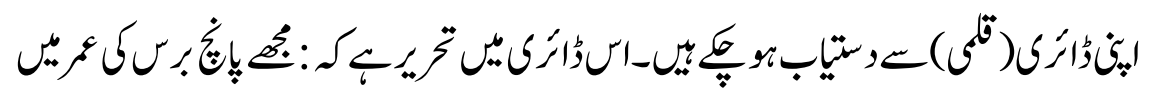

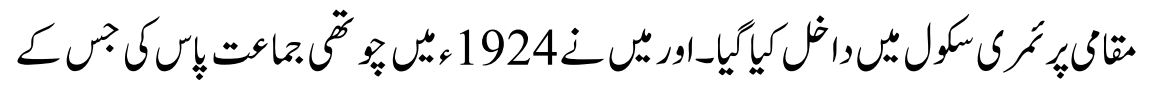

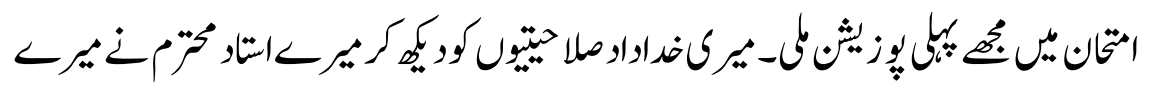

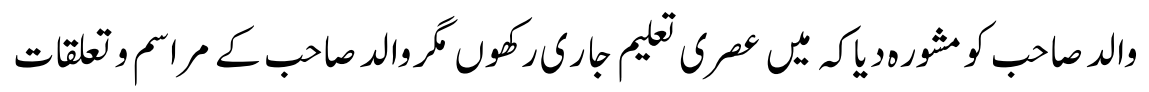

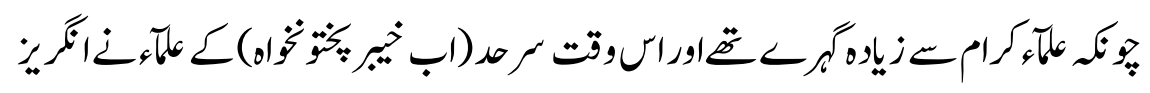

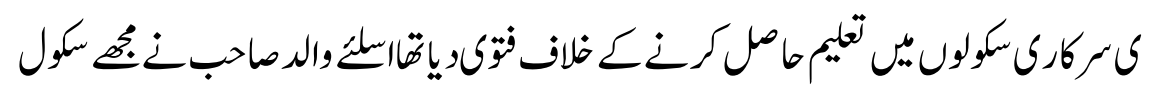

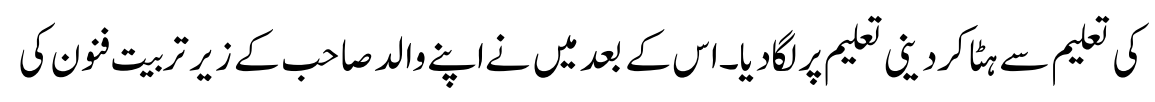

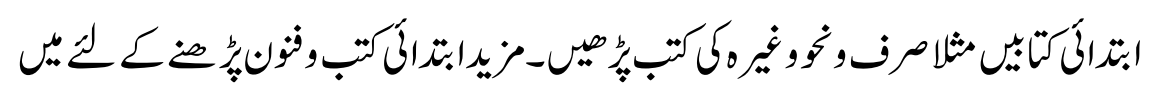

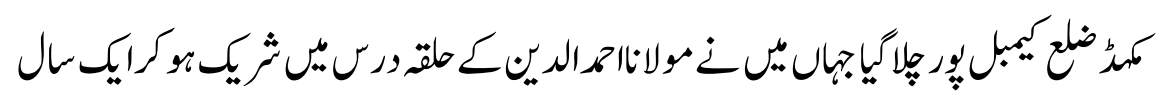

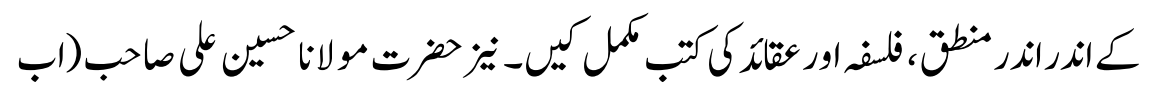

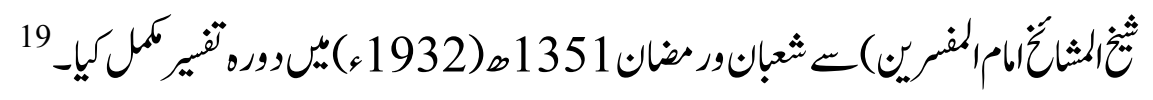

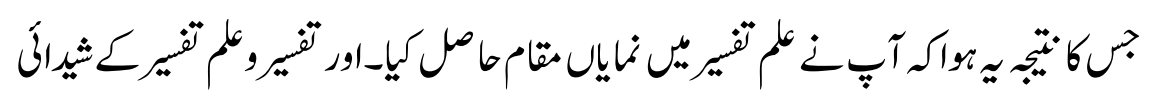

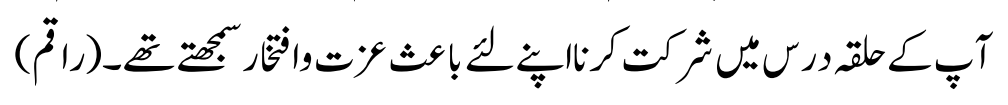

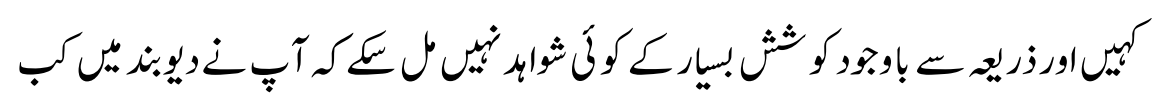

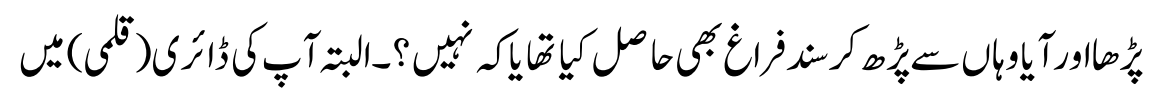

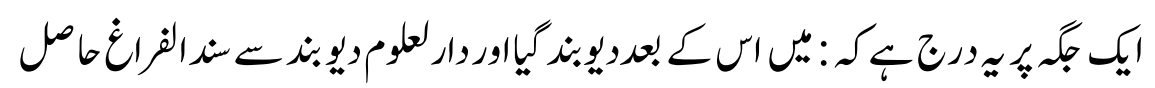

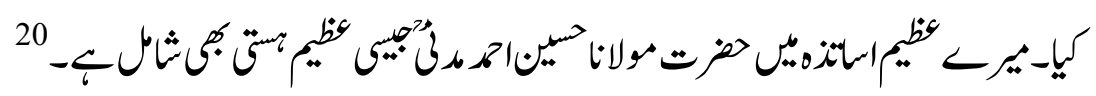




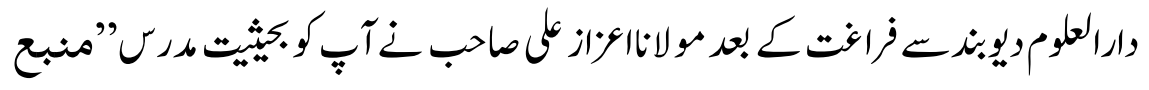

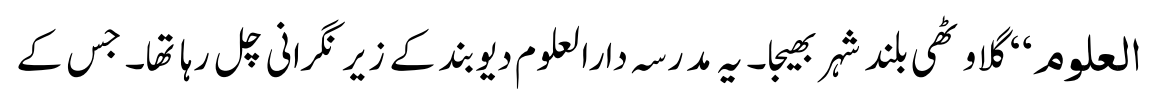

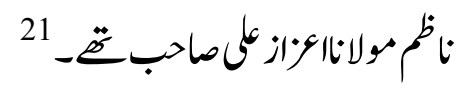

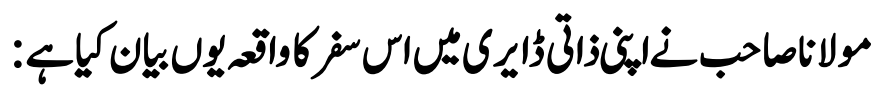

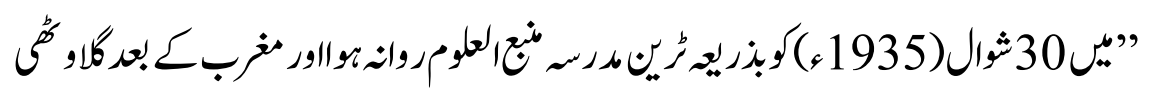

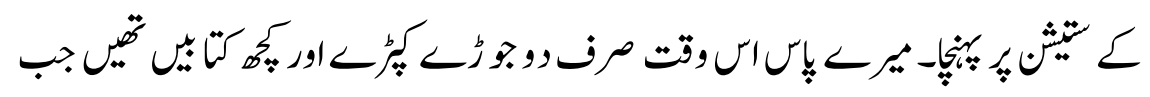

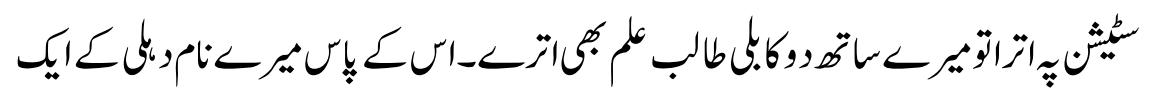

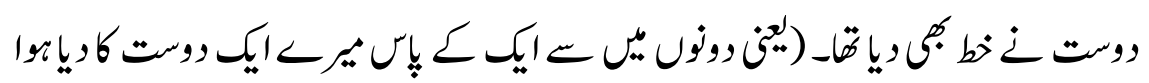

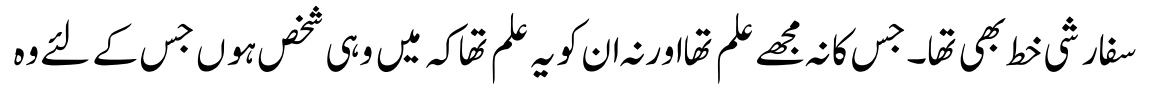

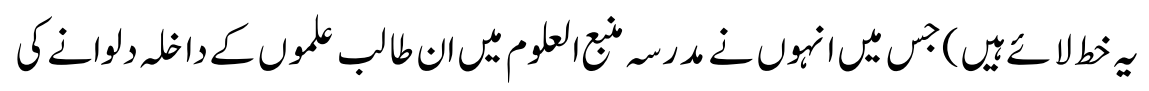

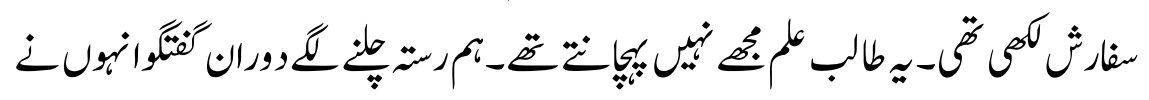

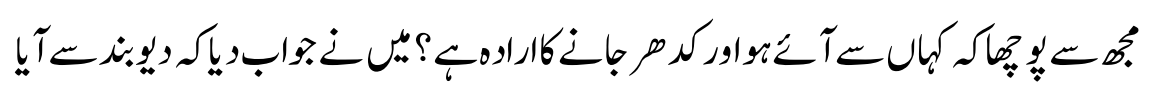

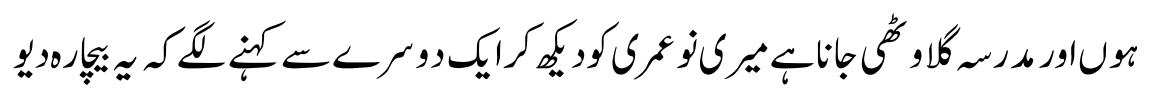

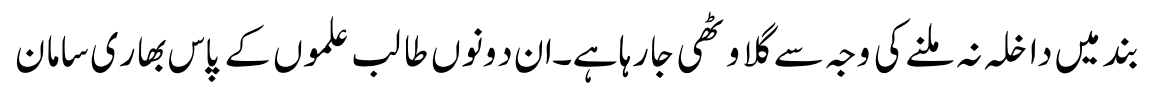

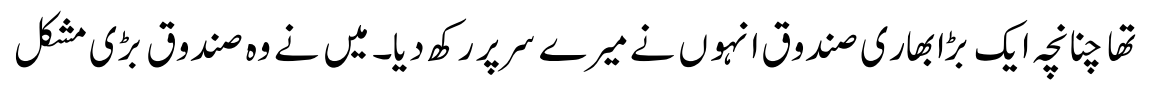

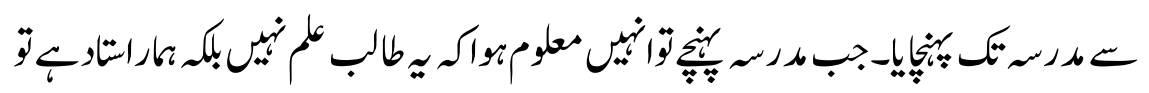

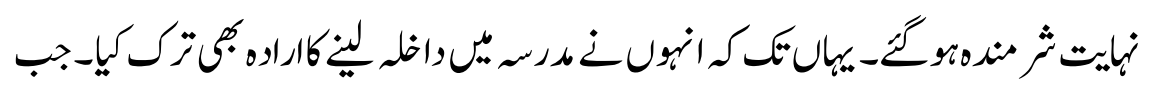

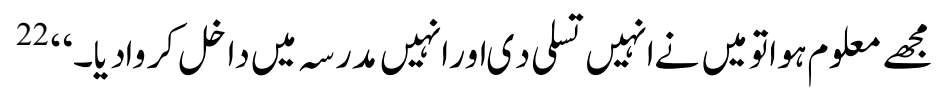

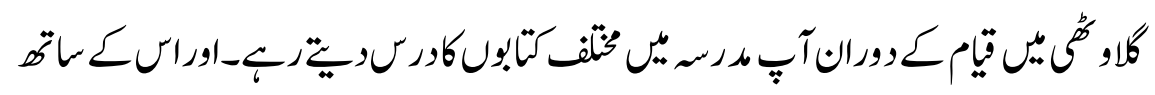

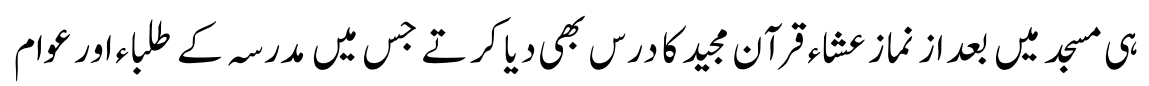

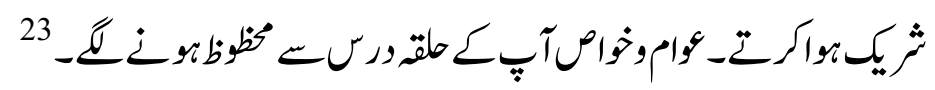




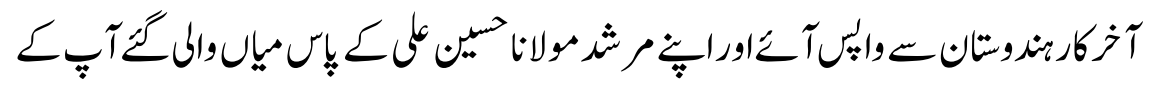

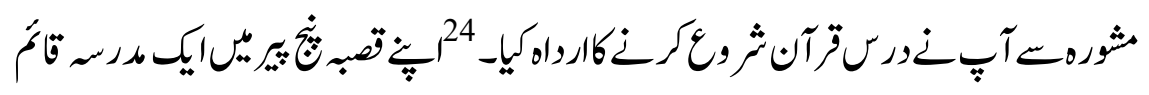

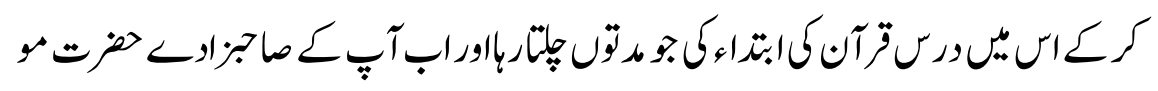

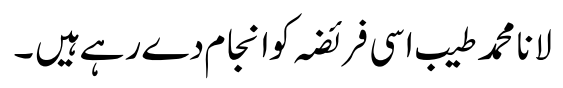

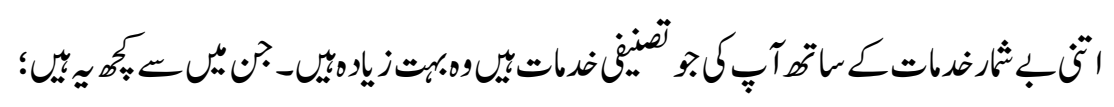
1- سمط السررفىربط الاياتو السوروخلاصتها الهختصر 2ـ اللمعانمنخلاصةسور القرآن(يثز) 3ـ العرفأنفاصولالقرآن 4- نيل السائرينفىطبقات الهفسرين 5ـ البصائرللهتوسلينباهل الهقابر

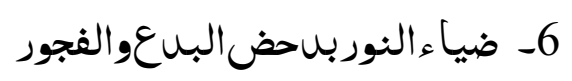
7ـ اصول السنةلر دالبلاعه 8ـ الانتصارلسنةسيuالابرار 9ـ انشاطمنحيلة الاسقاط

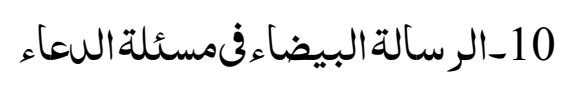

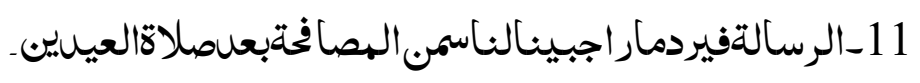

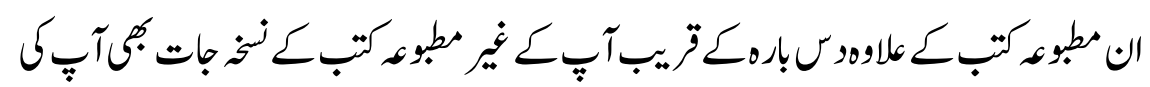

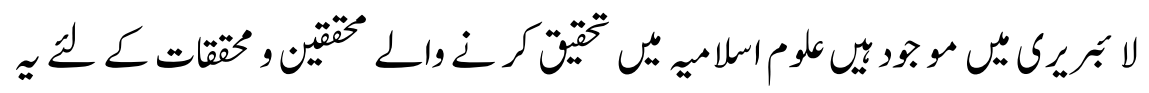

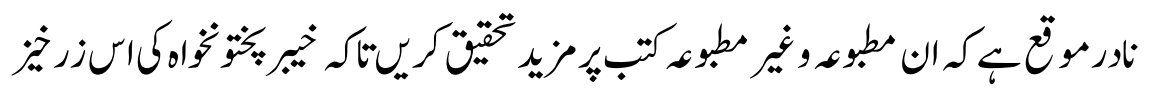

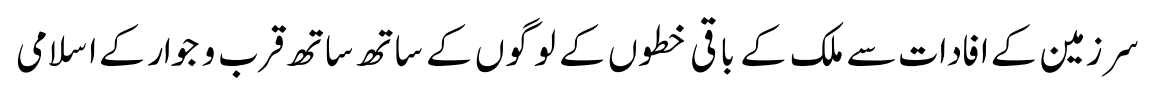

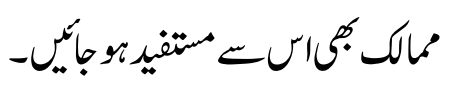




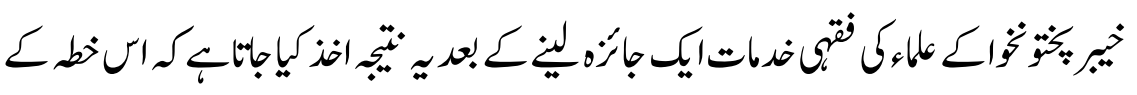

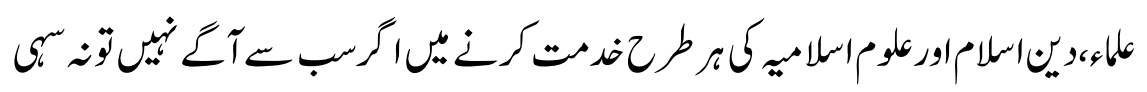

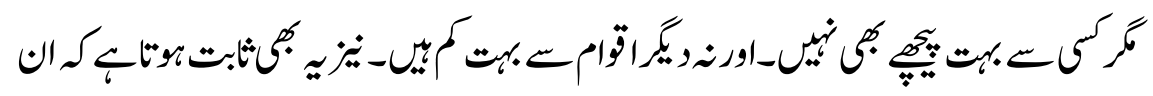

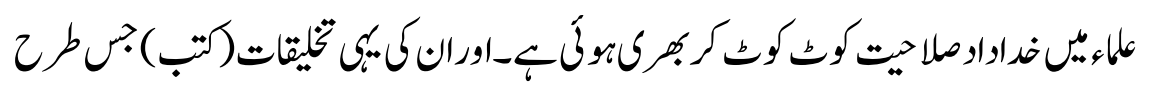

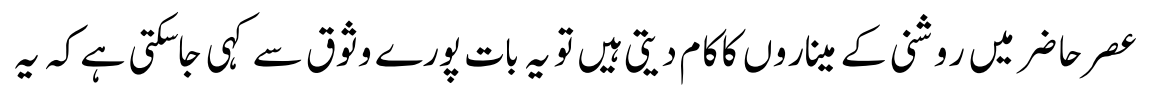

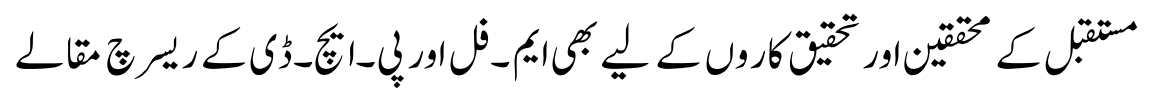

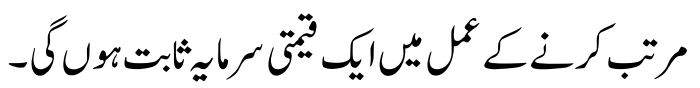

والـجات

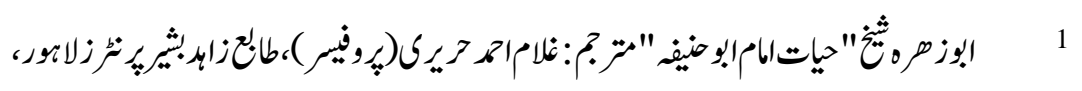
1983، 17 17

2 هور، تن نارو،ص:17-18 3 4

5 5 6

7

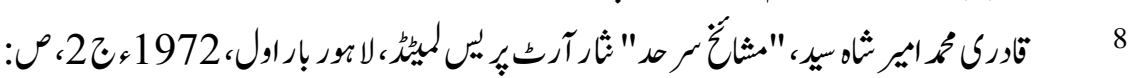

$$
\begin{aligned}
& 464 \\
& 9
\end{aligned}
$$




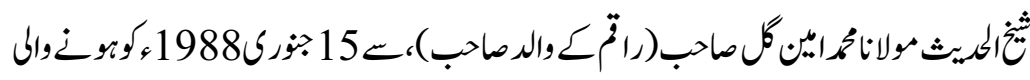

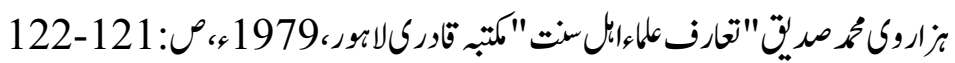

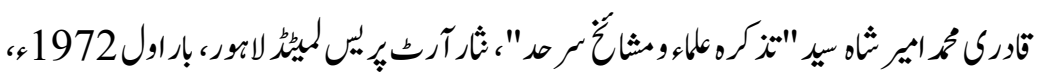

$$
\text { 223-222:ص:27 }
$$

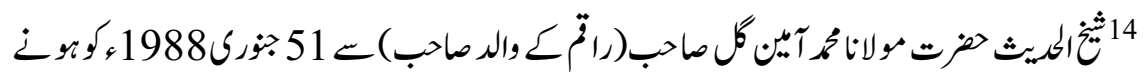

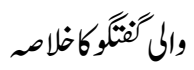

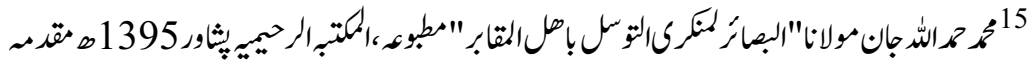
16 نفمصرد 17

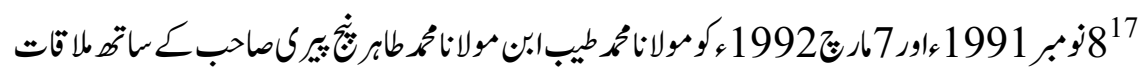

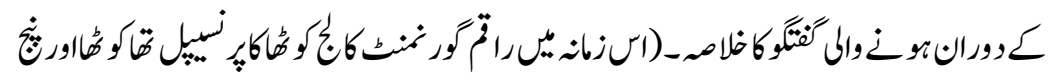

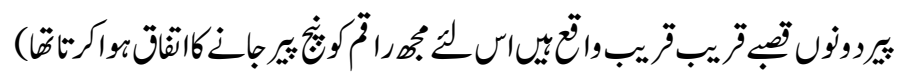
18 وتص:10

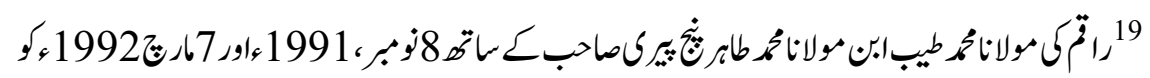

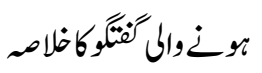

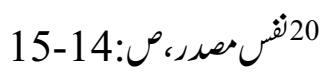
21

$$
\text { طباوت ص:14- }
$$

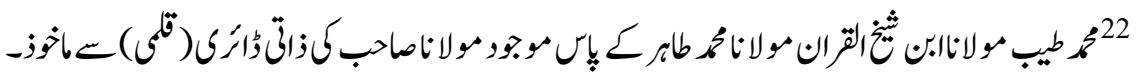

ص:17-16

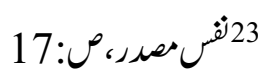
24نمن 24 